\title{
Prevalence and Determinants of Chronic Malnutrition among Preschool Children: A Cross-sectional Study in Dhaka City, Bangladesh
}

\author{
Aklima Jesmin', Shelby Suzanne Yamamoto², Ahmad Azam Malik², and Md. Aminul Haque² \\ 'Medicine Sans Frontires Belgium, Dhaka, Bangladesh and ${ }^{2}$ Institute of Public Health, Heidelberg University, Heidelberg, Germany
}

\begin{abstract}
Chronic malnutrition is one of the major causes of morbidity and mortality among preschool children and the future productivity of nations. To understand the prevalence of chronic malnutrition and to identify the factors affecting height-for-age z-score (HAZ) among preschool children, a cross-sectional study was conducted among 380 randomly-selected children aged less than five years in Dhaka city, Bangladesh. Results of analysis of this study data revealed that the prevalence of stunting among preschool children in Dhaka city was $39.5 \%$, with $25 \%$ severely stunted and $14 \%$ moderately stunted $(\mathrm{p}<0.001)$. Results of bivariate analysis revealed that socioeconomic and demographic factors were most significantly associated with the stunting of children. Children were found to be well-nourished if their parents had a tertiary-level education or higher and if the mother held a job and had good knowledge of nutrition. Well-nourishment of the children were also associated with the height of mothers (above $148 \mathrm{~cm}$ ), good family educational background, normal birthweight, greater frequency of food intake (more than six times/day), and fewer fever episodes in the last six months. Results of multivariate linear regression models showed that height of mothers, birthweight of children, education of fathers, knowledge of mothers on nutrition, and frequency of feeding were the most significant factors that had an independent and direct influence on the stunting of children. To achieve the Millennium Development Goal target of 34\% malnutrition prevalence by 2015 , it is important to have specific government intervention to focus on the causes that directly influence the stunting of children.
\end{abstract}

Key words: Child nutritional disorders; Child nutritional status; Cross-sectional studies; Stunting; Bangladesh

\section{INTRODUCTION}

Malnutrition continues to be a growing problem in most developing countries (1). Poor nutrition during childhood is one important factor impeding the physical and mental development of children, which ultimately propagates the vicious cycle of intergenerational malnutrition. The issue of child malnutrition is critical because its effects are not limited to the boundary of childhood but rather persist into adulthood. It silently destroys the future productivity of nations. Malnutrition increases the economic burden of a society because it leads to

Correspondence and reprint requests should be addressed to:

Dr. Md. Aminul Haque

Institute of Public Health

Heidelberg University

INF 324

60120 Heidelberg

Germany

Email: aminuldps@gmail.com increased risk of death from infectious diseases (2), more severe infections, and higher case fatalities (3), creating an additional psychosocial burden. In developing countries, it is estimated that $29 \%$ of children aged less than five years (under-five children) are stunted $[<-2$ standard deviation (SD) height-for-age] or chronically undernourished. Although stunting has declined from $47 \%$ in 1980 to $29 \%$ in 1995 , prevalences are still extremely high, especially in South Central Asia, which alone accounts for about half of the global problem (4). Studying stunting is important because it reflects the cumulative effects of socioeconomic, health and nutritional problems. Stunting is also a predictor of risk because it reflects the overall level of development characterized by poverty, low socioeconomic status, and the prevalence of chronic diseases. It is an important public-health problem in Bangladesh (5).

The prevalence of malnutrition is very high in Bangladesh and is one of the leading causes 
of morbidity and mortality in children $(6,7)$. Data of the Bangladesh Health and Demographic Survey (BDHS) 2007 show that the prevalence of stunted children is $43.2 \%$, a reduction from $51 \%$ in 2004 (8) . However, this decline still falls short of the Millennium Development Goal (MDG) 2015 target 34\% malnutrition prevalence (9). Currently, $36 \%$ of children are born in Bangladesh with low birthweight (4), and $19-27 \%$ are severely (10) to moderately stunted (11-13). More than $80 \%$ of young infants and $40 \%$ of pregnant women are anaemic. Around 400,000 under-five children have severe acute malnutrition, the most severe form of protein-energy malnutrition characterized by a weight-for-height z-score of $<-3$ or bilateral pedal oedema (14).

Child malnutrition is affected by several determinants, such as intrauterine growth retardation, lack of exclusivebreastfeeding, inappropriate complementary feeding, repeated attacks of infectious illnesses, food scarcity, and micronutrient deficiencies (14). The socioeconomic and demographic factors are, importantly, associated with severe and moderate stunting (15). These determinants also vary according to the seasons and spatial distributions of households in the country. The issue of malnutrition is very complex and influenced by multidimensional factors, which have not yet been explored. The present study aims to assess the prevalence of and factors associated with chronic malnutrition among preschool children in the urban setting of Dhaka city, Bangladesh.

\section{MATERIALS AND METHODS}

A cross-sectional study was conducted over a sixmonth period during 1 December 2007-20 May 2008 in randomly-selected wards (number 45 and 63), the smallest administrative unit of the Dhaka City Corporation, which consists of 90 wards. In total, 380 of 1,265 families were randomly selected that had at least one child aged 0-59 months. Mothers of the selected children were interviewed to obtain information on their socioeconomic, demographic and health and nutrition-related issues through pretested semi-structured questionnaires. The majority of the variables were constructed on an interval scale. Before analysis, the variables were transformed into categorical variables. Anthropometric data were obtained in the same manner to minimize the potential sampling errors. Weight of the child was measured in gramme, and height was measured in centimetre. For children aged less than two years, weight was calculated by subtracting the weight of the mother from the combined weight of the mother-child pair, and recumbent length was measured with a locally-made wooden stadio-meter. Age and the birthweights of children were recorded either from the mother or from the child's delivery discharge paper.

The prevalence of stunting was calculated according to the child growth standard of the World Health Organization (WHO) $(16,17)$. The Anthro 2005 software of the WHO was used for calculating the z-score. This study used the following malnutrition cut-off points recommended by the WHO: (a) severely stunted=z-score <-3 SD; (b) moderately stunted=z-score $(-3$ to $<-2 \mathrm{SD})$; (c) normal=z-score $(-2$ to $<+1 \mathrm{SD})$; (d) well-nourished=z-score $(+1$ to $<+2$ $\mathrm{SD})$; and (e) obese=z-score (above $+2 \mathrm{SD}$ ) (18-20).

The independent variables measured in the study included education, height, and nutritional knowledge of mother, education of father, amount of time father spends at home on childcare, monthly family income, birthweight, and frequency of complementary feeding of the child. The variableeconomic status-was calculated using assets or a wealth score, rather than income or consumption from the household survey questionnaire of the BDHS. Surveys included questions concerning the household's ownership of 21 of consumer items ranging from a fan to a television and car; dwelling characteristics, such as type of toilet facilities used; and other characteristics relating to wealth. The presence of each item in each household was given a score of 1 or 0 for each consumer item, depending on ownership and summed. Households were sorted into one of five economic score classes as follows:1-5=poor economic class; 6-10=lowermiddle class; $11-15=$ upper-middle class; and 1621=high-economic class (Cronbach's alpha coefficient $\alpha=0.86)$ (8).

The variable-family education-is an index of the combined level of education of the respondent, respondent's parents, in-laws, and husband. The total schooling years for all persons in the household were summed and a household mean was calculated. Household means were then coded as follows: very low=0-3; low=4-6; medium=7-10; high=11-14; and very high=15-17. A nutrition knowledge score was calculated based on the mother's responses to the health and nutrition-related items of the questionnaire (Cronbach's $\alpha=0.81$ ). The knowledge score for each mother was then subsequently divided into groups as follows: low $=3-6$; moderate $=7-11$; and high $=12-16$.

To observe the significant variations in the nutritional status of the children among different group means, one-way analysis of variance (ANOVA) using the Scheffe-test and independent sample Student's $t$-tests were applied. Stepwise multiple linear 
regression analysis was used for modelling the effects of the independent variables on stunting in children. Those variables which were significant at the $\alpha=0.05$ level were included in the final regression model. All analyses were completed using the SPSS software (version 15.0).

\section{Ethical approval}

The research evaluation committee of the Department of Population Sciences, University of Dhaka, approved the study. The respondents were informed about the study before interview, and their written informed consents were recorded.

\section{RESULTS}

The characteristics of the study children are summarized in Table 1 . Their socioeconomic profiles showed that more than $53 \%$ of mothers $(n=248)$ had no tertiary education (below graduation), and more than $82 \%$ were housewives. However, the nutrition knowledge of $67 \%$ of mothers was quite high.

Fathers were more educated than mothers. About $54 \%$ of fathers $(n=204)$ had at least 15 years of schooling whereas only $37 \%$ of the mothers had the same level of education. The majority (51.6\%) of the fathers spent more than two hours at home each day with their children. Family education of $57 \%$ of the respondents was recorded as below the medium level, with only $12.1 \%$ in the highest category. One quarter of the families had an income of up to Tk 10,000 (US\$ $1=$ Tk 68.5 in 2008). More than $30 \%$ of the mothers had a height below 149 $\mathrm{cm}$. More than $20 \%$ of the children had low birthweights (below 2,500 g). Around 26\% of the mothers gave complementary food (food other than breastmilk) less than four times per day.

Table 1 also presents the distribution of the heightfor-age z-scores (HAZ) of the study children according to their socioeconomic, demographic and feeding practices. Results of bivariate analysis showed that the mean HAZ was higher for children of mothers with a postgraduate degree (-0.6316). The primary (-2.256), secondary (-1.854) and higher secondary (-2.331) education groups significantly differed from the postgraduation group. The mean HAZ also showed that the nutritional status of children of working mothers was better compared to that of children of mothers who were housewives. Children of mothers who had good knowledge of nutrition also had significantly better nutritional status than children of mothers with poor nutritional knowledge. The HAZ also significantly varied with education of fathers, with the highest scores from the children of fathers who had postgraduate degrees. The mean HAZ was significantly higher in households where fathers spent more than two hours each day at home on childcare. There was also a significant difference in the mean HAZ between families with very low overall family education and very high family education levels $(\mathrm{p}=0.028)$. Additionally, the monthly family income was positively associated with the nutritional status of children, with a higher mean HAZ associated with the monthly family incomes of above Tk 10,000 . Height of the mothers was positively associated with the nutritional status of children. A significant difference $(\mathrm{p}=0.001)$ was also observed between the height of mothers and the mean z-score of the child. Birthweight was positively associated with nutritional status. Low-birthweight infants were more likely to develop into stunted (-2.396) children than children of normal birthweight (-1.589) and above normal birthweight (-0.849) (21).

Among factors relating to infant feeding, the frequency of complementary feeding was positively associated with the HAZ. In this study, the number of fever episodes in the last six months was negatively associated with the HAZ. There was a significant difference in the mean HAZ among children who did not suffer from fever and those who had between one and three fever episodes in the past six months. Children who suffered from fever for more than six times in the past six months were more likely to be severely stunted (-4.194)

\section{Prevalence of nutrition}

The prevalence of stunted children in the two wards is showed in Table 2 . More than $43 \%$ of the children were suffering from malnutrition. Of these malnourished children, 25\% and 14\% were severely and moderately stunted respectively. The prevalence of stunting among preschool children in Dhaka city was significant $(\mathrm{p}<0.001)$.

The above model explained $49 \%$ of the total variance (Table 3). Height of mothers, education of fathers, birthweight of children, knowledge of mothers on nutrition, and frequency of complementary feeding were the most significant factors for explaining the variance in the stunting of under-five children.

\section{DISCUSSION}

The study was conducted in a rapidly-growing and the most populated city of the country. The respondents, despite their use of available urban facilities, such as electricity, access to media, and sanitation, also suffered from air and sound pollution, insufficient water supply, and electricity shortages. Compared to the overall literacy rate of Bangladesh, the educational qualification of parents in this study was quite high. Despite a fair level of 


\begin{tabular}{|c|c|c|c|c|}
\hline \multirow{2}{*}{ Characteristics and categories } & \multicolumn{2}{|c|}{ Children } & \multicolumn{2}{|c|}{ HAZ } \\
\hline & $\%$ & No. & Mean & $p$ value \\
\hline \multicolumn{5}{|l|}{ Socioeconomic Factors } \\
\hline \multicolumn{5}{|l|}{ Education of mothers ${ }^{\star \star *}$} \\
\hline Primary & 17.6 & 67 & -2.256 & 0.001 \\
\hline Secondary & 17.9 & 117 & -1.854 & 0.011 \\
\hline Higher secondary & 18.2 & 64 & -2.331 & 0.001 \\
\hline Graduation & 18.4 & 62 & -1.331 & 0.519 \\
\hline Postgraduation ${ }^{\dagger}$ & 18.7 & 70 & -.632 & \\
\hline \multicolumn{5}{|l|}{ Work status of mothers ${ }^{\star \star *}$} \\
\hline Housewife ${ }^{*}$ & 82.1 & 312 & -1.875 & 0.001 \\
\hline Working mother ${ }^{\dagger}$ & 17.9 & 68 & -.865 & \\
\hline \multicolumn{5}{|c|}{ Knowledge of mothers on nutrition ${ }^{* * *}, \$$} \\
\hline Low & 2.4 & 9 & -4.002 & 0.002 \\
\hline Moderate & 30.3 & 115 & -2.338 & $<0.001$ \\
\hline $\operatorname{High}^{\dagger}$ & 67.4 & 256 & -1.325 & \\
\hline \multicolumn{5}{|l|}{ Education of fathers ${ }^{\star * \star}, \$$} \\
\hline Primary & 14.7 & 56 & -2.273 & 0.010 \\
\hline Secondary & 22.4 & 85 & -2.251 & 0.002 \\
\hline Higher secondary & 9.2 & 35 & -2.061 & 0.153 \\
\hline Graduation & 20.0 & 76 & -1.726 & 0.226 \\
\hline Postgraduation ${ }^{\dagger}$ & 33.7 & 128 & -.953 & \\
\hline \multicolumn{5}{|c|}{ Father's spending time (hours) at home ${ }^{* * *}$} \\
\hline$<1$ & 9.5 & 36 & -2.293 & 0.036 \\
\hline $1-2$ & 38.9 & 148 & -2.160 & 0.001 \\
\hline$>2^{\dagger}$ & 51.6 & 196 & -1.234 & \\
\hline \multicolumn{5}{|l|}{ Education of family ${ }^{\star *}$} \\
\hline Very low ${ }^{*}$ & 25.3 & 96 & -2.183 & 0.028 \\
\hline Low & 32.6 & 124 & -1.962 & 0.85 \\
\hline Medium & 25.5 & 97 & -1.385 & 0.770 \\
\hline High ${ }^{\dagger}$ & 12.1 & 46 & -.839 & \\
\hline \multicolumn{5}{|l|}{ Socioeconomic class* } \\
\hline Low & 11.1 & 42 & -2.388 & 0.141 \\
\hline Lower-middle class & 32.1 & 122 & -1.934 & 0.396 \\
\hline Upper-middle class & 40.5 & 154 & -1.466 & 0.980 \\
\hline Upper ${ }^{\dagger}$ & 16.3 & 62 & & \\
\hline \multicolumn{5}{|l|}{ Monthly family income (Tk) ${ }^{\star \star \star}$} \\
\hline$<10,001^{\dagger}$ & 25 & 95 & -2.368 & \\
\hline $10,001-20,000^{*}$ & 31.8 & 121 & -1.406 & 0.009 \\
\hline$>20,000^{*}$ & 43.2 & 164 & -1.517 & 0.015 \\
\hline \multicolumn{5}{|l|}{ Demographic factors } \\
\hline \multicolumn{5}{|l|}{ Birthweight of children $(\mathrm{g})^{\star * \star}, \$$} \\
\hline Low birthweight $(<2,500 \mathrm{~g})^{\dagger}$ & 20.5 & 78 & -2.396 & \\
\hline Normal weight $^{*}$ & 67.6 & 257 & -1.589 & 0.019 \\
\hline Above normal weight ${ }^{*}$ & 11.8 & 45 & -.849 & 0.001 \\
\hline \multicolumn{5}{|l|}{ Height $(\mathrm{cm})$ of mothers ${ }^{* * *}, \$$} \\
\hline$\leq 148$ & 30.3 & 115 & -2.841 & $<0.001$ \\
\hline$>148$ & 69.7 & 265 & -1.157 & \\
\hline
\end{tabular}




\begin{tabular}{|c|c|c|c|c|}
\hline \multirow{2}{*}{ Characteristics and categories } & \multicolumn{2}{|c|}{ Children } & \multicolumn{2}{|c|}{ HAZ } \\
\hline & $\%$ & No. & Mean & p value \\
\hline \multicolumn{5}{|c|}{ Infant-feeding practice-related factor } \\
\hline \multicolumn{5}{|c|}{ Frequency (times) of complementary feeding ${ }^{\star \star \star}, \$$} \\
\hline$<4$ & 25.8 & 98 & -2.345 & 0.001 \\
\hline 4-6 & 70.5 & 268 & -1.375 & $<0.001$ \\
\hline \multicolumn{5}{|l|}{ Sickness-related factors } \\
\hline \multicolumn{5}{|c|}{$\begin{array}{l}\text { No. (times) of fever episodes in the } \\
\text { past } 6 \text { months* }\end{array}$} \\
\hline No fever & 38.9 & 150 & -1.522 & 0.022 \\
\hline $1-3$ & 48.9 & 186 & -1.654 & 0.033 \\
\hline 4-6 & 9.7 & 37 & -1.838 & 0.086 \\
\hline$>6$ & 1.8 & 7 & -4.197 & \\
\hline
\end{tabular}

nutritional knowledge of the mothers, the prevalence $(43 \%)$ of malnutrition among the preschool children was very high. The multivariate results revealed that the practical knowledge of mothers about nutrition was more important for the nutritional status of children than the formal education of mothers. Improved knowledge of the mothers on nutrition significantly reduced the risk of stunting. Conversely, unlike the education of mothers, the education of fathers independently influenced the nutritional status of children. The results of multiple linear regression showed that a one-year increase in schooling of the father can reduce 11\% of stunting in children. Apart from stunting, another finding of the study was the emergence of overweight and obesity which are also important public-health concern in the study area.

Stunting is a predictor of risk as it reflects the overall level of development characterized by poverty, low socioeconomic status, and the prevalence of chronic diseases (15). Nutritional status is related to physical, mental, social and intellectual growth, beginning with foetal development, infancy, and childhood and extending to adolescence and adulthood. Among the demographic factors, birthweight of a child is also a significant factor affecting

\begin{tabular}{|lccc|}
$\begin{array}{l}\text { Table 2. Prevalence of stunted children among } \\
\text { study subjects }\end{array}$ \\
\hline Nutritional status & Frequency & $\%$ & p value \\
\hline Severely stunted & 96 & 25.3 & \\
Moderately & & & \\
stunted & 54 & 14.2 & $<0.001$ \\
Normal & 191 & 50.3 & \\
Well-nourished & 24 & 6.3 & \\
Obese & 15 & 3.9 & \\
\hline
\end{tabular}

the risk of stunting as has been found in another study (15).

\section{Limitation}

A limitation of the present study was that, while conducting the interviews, we had to depend on the information provided by mothers. Information could, thus, have been subject to recall bias. However, we were careful in recording the information they provided and in the interpretation of the results of the study.

\section{Conclusions}

Within the context of the socioeconomic, demographic, educational and spatial factors, the

\begin{tabular}{|c|c|c|c|c|}
\hline Determinant & $\mathrm{b}$ & $\beta$ & $\mathrm{R}^{2}$ change & p value \\
\hline Height of mother & 0.087 & 0.349 & 0.158 & 0.000 \\
\hline Education of father & 0.049 & 0.113 & 0.043 & 0.031 \\
\hline Birthweight of child & 0.408 & 0.130 & 0.020 & 0.007 \\
\hline Knowledge of mother on nutrition & 0.096 & 0.109 & 0.011 & 0.036 \\
\hline Frequency of complementary feeding & 0.160 & 0.097 & 0.009 & 0.041 \\
\hline
\end{tabular}


high level of stunting is very much unexpected. People come to the city for better job opportunities, additional income, quality education, improved health, and a healthier future. However, the high level of stunting reflects the drawbacks and problems associated with urban life. To reduce the rates of child mortality and morbidity and to achieve the MDG targets, necessary measures are needed to inform urban families about the high prevalence of malnutrition among their children and to reduce the existing level of stunting.

\section{ACKNOWLEDGEMENTS}

The authors express their gratitude to the United Nations Population Fund and the Department of Population Sciences, University of Dhaka, for financing the study. They are also grateful to all the families who contributed directly and indirectly to the study.

\section{REFERENCES}

1. Devi PY, Geervani P. Determinants of nutritional status of rural pre-school children in Andhra Pradesh, India. Food Nutr Bull 1994;15:335-42.

2. Chen LC, Chowdhury A, Huffman SL. Anthropometric assessment of energy-protein malnutrition and subsequent risk of mortality among preschool aged children. Am J Clin Nutr 1980;33:1836-45.

3. Bardosono S, Sastroamidjojo S, Lukito W. Determinants of child malnutrition during the 1999 economic crisis in selected poor areas of Indonesia. Asia Pac J Clin Nutr 2007;16:512-26.

4. United Nations. $4^{\text {th }}$ report-the world nutrition situation: nutrition throughout life cycle. Final report to the ACC/SCN by the Commission on the Nutrition Challenges of the $21^{\text {st }}$ Century. New York, NY: United Nations, 2000:1-144. (http://www.unscn.org/layout/ modules/resources/files/rwns4.pdf, accessed on 10 November 2010).

5. de Onis M, Blossner M. The World Health Organization global database on child growth and malnutrition: methodology and applications. Int J Epidemiol 2003;32:518-26.

6. Alam N, Wojtyniak B, Rahaman MM. Anthropometric indicators and risk of death. Am J Clin Nutr 1989;49:884-8.

7. Bairagi R, Chowdhury MK. Socioeconomic and anthropometric status, and mortality of young children in rural Bangladesh. Int J Epidemiol 1994;23:1179-84.

8. National Institute of Population Research and Training. Bangladesh demographic and health survey, 2007. Dhaka: National Institute of Population Research and Training, 2007. 346 p.

9. Ahmed T. Policy brief on child and maternal nutrition in Bangladesh. Bangladesh demographic and health survey 2007. Dhaka: National Institute of Population
Research and Training, 2007. (http://www.bmj.com/ content/339/bmj.b4490.full, accessed on 10 November 2010).

10. Bangladesh Bureau of Statistics. National low birth weight survey of Bangladesh, 2003-2004. Dhaka: Bangladesh Bureau of Statistics, 2005. 67 p.

11. Bangladesh Bureau of Statistics. Child and mother nutrition survey of Bangladesh, 2005. Dhaka: Bangladesh Bureau of Stastics, 2005. $111 \mathrm{p}$.

12. Jahan K, Hossain M. Nature and extent of malnutrition in Banagladesh: Bangladesh national nutrition survey. Dhaka: Institute of Nutrition and Food Science, University of Dhaka, 1998. 176 p.

13. National Institue of Population Research and Training. Bangladesh demographic and health survey 1999 -2000. Dhaka: National Institute of Population Research and Training, 2001. $211 \mathrm{p}$.

14. Ahmed T, Ahmed AMS. Reducing the burden of malnutrition in Bangladesh. BMJ 2009;339:b4490.

15. Rahman A, Chowdhury S. Determinants of chronic malnutrition among preschool children in Bangladesh. J Biosoc Sci 2007;39:161-73.

16. World Health Organization. Child growth standards: length/height-for-age, weight-for-age, weightfor-length, weight-for-height and body mass indexfor-age: methods and development. Geneva: World Health Organization, 2006. 312 p.

17. World Health Organization. Child growth standards: growth velocity based on weight, length and head circumference: methods and development. Geneva: World Health Organization, 2009. 242 p.

18. de Onis M, Onyango AW, Borghi E, Garza C, Yang $\mathrm{H}$; WHO Multicentre Growth Reference Study Group. Comparison of the World Health Organization (WHO) child growth standards and the National Center for Health Statistics/WHO international growth reference: implications for child health programmes. Public Health Nutr 2006;9:942-7.

19. Schwarz NG, Grobusch MP, Decker ML, Goesch J, Poetschke M, Oyakhirome S et al. WHO 2006 child growth standards: implications for the prevalence of stunting and underweight-for-age in a birth cohort of Gabonese children in comparison to the Centers for Disease Control and Prevention 2000 growth charts and the National Center for Health Statistics 1978 growth references. Public Health Nutr 2008;11:714-9.

20. Nuruddin R, Lim MK, Hadden WC, Azam I. Comparison of estimates of under-nutrition for pre-school rural Pakistani children based on the WHO standard and the National Center for Health Statistics (NCHS) reference. Public Health Nutr 2009;12:716-22.

21. Baby 2 See. Newborn baby weight information: big and small babies. Baby 2 See. 2010. 6 p. (http://www. baby2see.com/baby_birth_weight.html, access on 10 November 2010). 